\title{
MONITORAMENTO DE INDICADORES GEOQUÍMICOS E AVALIAÇÃO DE BIODEGRADAÇÃO EM ÁREA CONTAMINADA COM ÓLEO DIESEL
}

\section{MONITORING OF GEOCHEMICAL INDICATORS AND BIODEGRADATION EVALUATION AT A SITE CONTAMINATED WITH DIESEL OIL}

\begin{abstract}
Adriano Pinto Mariano
Engenheiro Químico pela UNICAMP. Especialista em Engenharia Ambiental (UNICAMP). Mestre em Engenharia Química pela Faculdade de Engenharia Química (FEQ/UNICAMP). Doutor em Geociências e Meio Ambiente pelo IGCE/UNESP. Participante do Programa de Formação de Recursos Humanos da Agência Nacional do Petróleo (PRH-05: Geologia do Petróleo e Ciências Ambientais Aplicadas ao Setor de Petróleo e Gás)
\end{abstract}

\section{DEJANIRA DE FRANCESCHI DE ANGELIS}

Bióloga pela UNESP. Doutora em Ciências (UNESP). Livre docente do Departamento de Bioquímica e Microbiologia do Instituto de Biociências da UNESP (Campus de Rio Claro)

\section{DANIEL MARCos BonotTo}

Físico pela UNESP. Doutor em Ciências (USP). Pós-doutorado (Universidade de Bath, Inglaterra). Livre docente do Instituto de Geociências e Ciências Exatas da UNESP (Campus de Rio Claro)

$$
\text { Código ABES: 030/07 Recebido:28/02/07 Aceito: 29/06/07 }
$$

\section{RESUMO}

A biorremediação natural da água subterrânea contaminada com óleo diesel em um posto de combustíveis foi avaliada mediante o monitoramento de indicadores geoquímicos e ensaios laboratoriais de biodegradação. Durante um período de dois anos foram realizadas quatro coletas de água subterrânea para a avaliação de diversos parâmetros físico-químicos e a concentração de hidrocarbonetos. As análises microbiológicas consistiram na contagem de bactérias heterotróficas totais, na verificação da presença de bactérias hidrocarbonoclásticas e no teste de biodegradabilidade utilizando o indicador redox DCPIP. Foi possível identificar fatores que corroboram o emprego da técnica de biorremediação natural para o tratamento da água subterrânea, contudo, a presença de hidrocarbonetos retidos no solo representa uma fonte contínua de contaminação, por isso se faz necessário o monitoramento a longo prazo.

PALAVRAS-CHAVES: Biorremediação natural, indicadores geoquímicos, água subterrânea, postos de combustíveis.

\begin{abstract}
The natural bioremediation of the groundwater contaminated with diesel oil at a petrol station was evaluated by monitoring geochemical indicators and biodegradation tests in laboratory. During two years the groundwater was collected four times. Different physic-chemical parameters and the concentration of hydrocarbons were evaluated. Microbiological analyses consisted of total heterotrophic bacteria counting, verification of the presence of hydrocarbonoclastic bacteria and the biodegradability test using the redox indicator DCPIP. It was possible to identify factors that confirm the use of the natural bioremediation technique as a treatment to the groundwater, however, hydrocarbons retained in the soil represent a continuous source of contamination, and for this reason, a long term monitoring is necessary.
\end{abstract}

KEYWORDS: Natural bioremediation, geochemical indicators, groundwater, petrol stations.

\section{INTRODUÇÃO}

Atualmente inúmeras pesquisas relacionadas à remediação de áreas atingidas por hidrocarbonetos são realizadas com a finalidade de restaurar a qualidade dos solos e das águas subterrâneas contaminadas. Vários métodos podem ser empregados para remover hidrocarbonetos do solo e água subterrânea tais como extração de vapor do solo, bombeamento e biorremediação. Não há uma regra geral que determine o melhor tratamento de uma área con- taminada específica. Cada caso deve ser analisado individualmente, avaliando suas particularidades.

Tratamentos físicos separam os contaminantes do solo sem destruí-los ou modificá-los quimicamente, mas apresentam muitas limitaçôes, destacando-se o custo alto. Quando os hidrocarbonetos percolam o solo, grande quantidade permanece sorvida na matriz (aproximadamente 50\%) com isso diminuindo a eficiência de remoção. Processos biológicos, por outro lado, são uma tecnologia promissora para remover esses contaminantes principalmente devido à simplicidade e eficiência de custo quando comparados a outras alternativas (Alexander, 1994).

Biorremediação pode ser considerada como uma nova tecnologia para tratar locais contaminados mediante o uso de agentes biológicos capazes de modificar ou decompor poluentes alvos. Estratégias de biorremediação incluem: a utilização de microrganismos autóctones, ou seja, do próprio local, sem qualquer interferência de tecnologias ativas de remediação (biorremediação intrínseca 
ou natural); a adição de agentes estimulantes como nutrientes, oxigênio e biossurfactantes (bioestimulação); e a inoculação de consórcios microbianos enriquecidos (bioaumento) (Bento et al, 2003; Mariano et al, 2007). O benefício desses processos é a mineralização do poluente, isto é, a transformação em gás carbônico, água e biomassa.

Recentemente, o interesse em utilizar a estratégia da atenuação natural monitorada (que inclui além da biodegradação outros processos como advecção, diluição, dispersão, sorção e volatilização) como técnica de tratamento de águas subterrâneas contaminadas com hidrocarbonetos é crescente em oposição a técnicas ativas de engenharia como a tecnologia de bombeamento e tratamento (Walt e McNab Jr., 1999). A biorremediação natural mostra-se interessante devido principalmente aos baixos custos e por ser uma técnica com intervenção mínima (Bhupathiraju et al, 2002).

A verificação da ocorrência da biorremediação natural exige a caracterização da geologia, hidrologia e ecologia microbiana locais, e também o conhecimento de processos biogeoquímicos. Para a biodegradação dos hidrocarbonetos é essencial uma reação de oxi-redução, em que o hidrocarboneto é oxidado (doador de elétron) e um aceptor de elétron é reduzido. Existem diferentes compostos que podem agir como aceptores de elétrons, entre eles o oxigênio $\left(\mathrm{O}_{2}\right)$, o nitrato $\left(\mathrm{NO}_{3}^{-}\right)$, os óxidos de $\mathrm{Fe}$ (III), o sulfato $\left(\mathrm{SO}_{4}^{-2}\right)$. Assim, mediante o acompanhamento da evolução espacial e temporal da concentração desses indicadores geoquímicos presentes na água subterrânea, é possível verificar como está ocorrendo a biorremediação natural de um local contaminado. Além dos aceptores de elétrons, outras variáveis podem ser relacionadas a processos biológicos, como o $\mathrm{pH}$ e o potencial redox (Vroblesky e Chapelle, 1994; Borden et al,1995; Corseuil e Alvarez, 1996; Walt e McNab, 1999; Azadpour-Keeley et al, 1999; Kao e Wang, 2000; Silva et al, 2002; Bhupathiraju et al, 2002; Röling e Versevel, 2002; Hunkeler et al, 2002, Cheon et al, 2004). Como limitaçôes da biorremediação natural são apontadas principalmente o longo tempo necessário, o risco da pluma de contaminação não ser atenuada antes de atingir pontos de abastecimento de água (Corseuil e Marins, 1997) e a aprovação pelo órgão ambiental (Mariano, 2006).

Outro ponto a ser considerado na execução de tratamentos biológicos é a necessidade de testes laboratoriais prévios para se determinar o potencial microbiológico em degradar determinado poluente num local específico (Cunha e Leite, 2000).

Neste contexto, o objetivo deste trabalho foi avaliar a biorremediação natural da água subterrânea em um posto de combustíveis, onde ocorreu vazamento de óleo diesel e conseqüente contaminação do solo e da água subterrânea, mediante o monitoramento de indicadores geoquímicos e também a realização de ensaios de biodegradação em laboratório como suporte para a determinação do potencial de remoção de poluentes pelos microrganismos presentes na área.

\section{DESCRIÇÃO DA ÁREA DE ESTUDÓ}

O posto de combustíveis está localizado no município de Santa Bárbara d'Oeste (22 45'15" S e 4724' 58” W) a $138 \mathrm{~km}$ da capital paulista, geologicamente situado na Bacia sedimentar do Paraná sobre o Sistema Aqüífero Tubarão (ou Itararé) e os aqüíferos Diabásio e Cenozóico, cada qual com diferentes características de ocorrência e circulação de água subterrânea (Waterloo, 1999).

No ano de 1994 foi constatado vazamento em um tanque de armazenamento subterrâneo de combustível com óleo diesel, o qual na época foi imediatamente isolado e retirado. Os trabalhos de avaliação de impacto ambiental na área começaram em 1999. Inicialmente foram conduzidas 12 sondagens de solo, seguidas da instalação de 4 poços de monitoramento. Nesta avaliação inicial não foi verificada a presença de fase livre de combustível, tanto nos furos das sondagens como na instalação dos poços de monitoramento (Waterloo, 1999).

A região próxima ao posto de combustíveis é caracterizada por uma ocupação essencialmente residencial, com ocorrência de alguns comércios locais de pequeno porte, não sendo observadas grandes lojas comerciais, shopping center, terminais de transporte coletivo ou outro tipo de atividade que favoreça a concentração de pessoas. A pavimentação das ruas vizinhas ao posto é de asfalto na sua totalidade, não existindo ruas pavimentadas com paralelepípedos. $\mathrm{Na}$ área localizada nas vizinhanças do posto, o abastecimento público de água e a coleta de esgoto são feitos pelo Departamento de Águas e Esgoto (DAE). Em um raio de $500 \mathrm{~m}$ a partir do posto, não foi identificado nenhum poço particular ou público de captação de água subterrânea (Waterloo, 1999).

$\mathrm{Na}$ área foram construídos 4 poços de monitoramento para a caracterização hidrogeológica e verificação de contaminação associada à água subterrânea (atualmente somente 3 poços estão disponíveis). Foram identificados quatro horizontes geológicos no local (Waterloo, 1999): aterro areno-siltoso $(0,15$ a $0,30 \mathrm{~m})$; silte arenoso levemente consolidado (0,42 a $1,16 \mathrm{~m})$; areia siltosa consolidada $(0,90$ a 2,85 m); arenito pouco alterado de dureza média a alta $(2,85 \mathrm{~m})$.

$\mathrm{Na}$ área de interesse foi identificado até a profundidade investigada (em torno de $5 \mathrm{~m}$ ) um aqüífero de caráter livre, anisotrópico e heterogêneo, associado aos tipos litológicos descritos anteriormente. Os três primeiros horizontes não apresentam estratificação sedimentar, sendo a heterogeneidade textural e granulométrica sua característica mais marcante; a estratificação plano-paralela aparece a partir do quarto horizonte e constitui uma variável hidrogeológica importante (Waterloo, 1999).

A partir de testes de formação do tipo slug test, o valor da condutividade hidráulica média obtida foi de $5,38 \cdot 10^{-4} \mathrm{~cm} / \mathrm{s}$. O nível d'água médio obtido foi de $1,79 \mathrm{~m}$. Com base nas cargas hidráulicas obtidas nos poços de monitoramento, foi elaborado um mapa potenciométrico para a área, o qual é apresentado na Figura 1. Nele pode-se observar que o sentido geral de fluxo é de sul para o norte seguindo a topografia local. O gradiente hidráulico médio observado no mapa potenciométrico é de 3\%. Os valores de condutividade hidráulica obtidos para o local são característicos de aqüíferos constituídos por materiais silto-arenosos, conforme a classificação feita por Freeze e Cherry (1979). Segundo o estudo feito por Gelhar et al. (1992), os valores de porosidade total e efetiva para os aquíiferos de composições litológicas semelhantes ao da área de interesse são em torno de $25 \%$. A velocidade média 
de escoamento calculada com base na Lei de Darcy foi de $6,46.10^{-5} \mathrm{~cm} / \mathrm{s}$ ou $5,58 \mathrm{~cm} / \mathrm{dia}$. Por outro lado, considerando-se o menor e o maior valor de condutividade hidráulica obtidos nos slug tests, tem-se que a velocidade da água para a área pode variar entre 1,84 e $12,13 \mathrm{~cm} /$ dia (Waterloo, 1999).

\section{METODOLOGIA}

\section{Amostragem da água subterrânea}

Foram realizadas quatro coletas de água subterrânea através dos poços de monitoramento SB1, SB2 e SB3 (Figura 1) em um intervalo de dois anos entre Maio de 2004 e Abril de 2006. Em cada coleta, inicialmente realizou-se a medição da profundidade do nível d'água (nível estático) e em seguida procedeu-se o esgotamento dos poços de monitoramento e após a recuperação dos poços, realizou-se as mediçóes de temperatura e condutividade elétrica, ambas com a sonda YSI 3000 TLC. Para a coleta das amostras de água subterrânea, foram utilizados amostradores descartáveis do tipo bailer. As amostras foram transferidas para diferentes frascos de coleta de acordo com a finalidade da análise: BTEX (vial com septo exposto faceado de teflon, $40 \mathrm{~mL}$ ); HPA, hidrocarbonetos policíclicos aromáticos, (frasco de vidro âmbar, $1 \mathrm{~L}$ ); análises físico-químicas (frascos plásticos, $2 \mathrm{~L}$ ); análises microbiológicas (tubos de cultura com rosca, $10 \mathrm{~mL}$, previamente autoclavados para assegurar a esterilidade).

\section{Determinações físico-químicas}

Em campo foram realizadas medidas de oxigênio dissolvido (Hanna HI 9142). Determinações de $\mathrm{pH}$ (Analion IA601) e Eh (Hanna HI 8314) foram realizadas em laboratório no mesmo dia da coleta. O eletrodo de $\mathrm{Ag} / \mathrm{AgCl}$ (Orion 9002) utilizado na leitura do potencial redox foi calibrado utilizandose uma solução contendo um par redox estável e conhecido (Zobell, 1946).

Em laboratório, as concentrações dos íons nitrato, sulfato, fosfato, potássio, cálcio, magnésio e ferroso foram determinadas com o espectrofotômetro Hach (DR 2000) utilizando-se a metodologia Hach (1992). A determinação de cloreto foi conduzida utilizando-se o

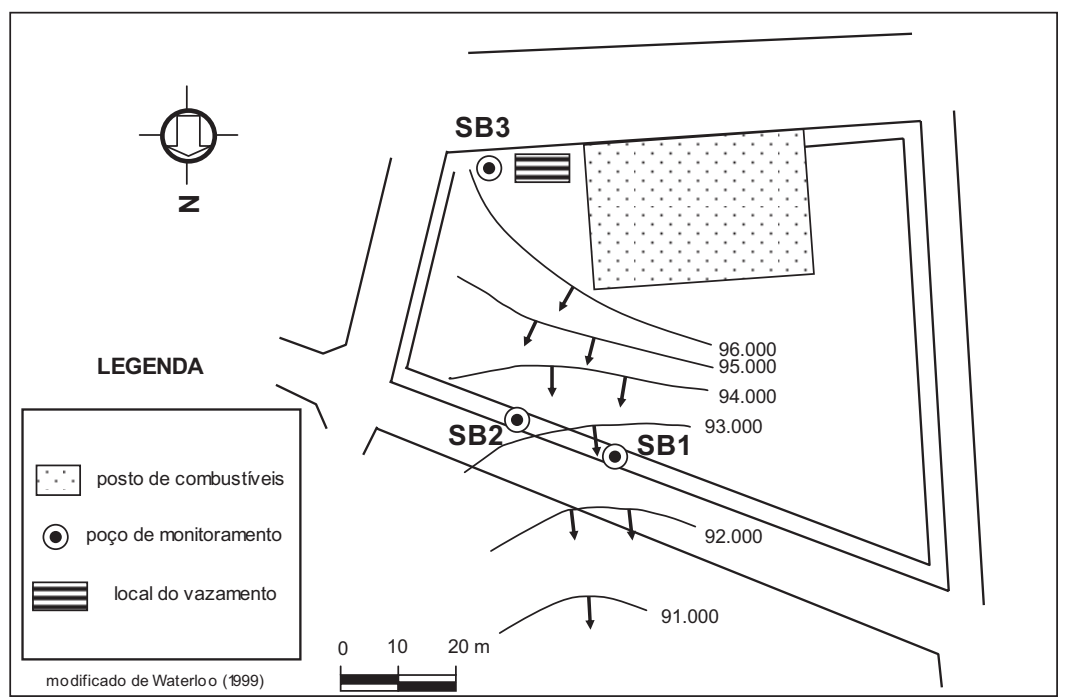

Fonte: modificado de Waterloo (1999).

Figura I- Mapa da área onde está localizado o posto de combustíveis e seus poços de monitoramento (SBI, SB2 e SB3)

eletrodo íon seletivo Orion modelo 9417B e o eletrodo de referência Orion modelo 9002 acoplados ao analisador de íons Analion IA601. Para a calibração foram utilizados padróes de concentraçóes conhecidas e compatíveis com o esperado para as amostras (Tonetto e Bonotto, 1999).

As determinaçôes de sódio para as três primeiras coletas foram efetuadas por espectrofotometria de absorção atômica (FAAS), utilizando-se o espectrofotômetro GBC 608 no Laboratório de Geoquímica (LABOGEO) no IGCE/Unesp. Para a última coleta, utilizou-se o eletrodo combinado Orion (8611BN) acoplado ao analisador de íons.

A alcalinidade total foi determinada através da técnica de titulação (metodologia Hach (1992)) usando uma solução padrão de ácido sulfúrico $(0,020 \mathrm{~N})$ até que o ponto final fosse evidenciado pela mudança de cor da solução indicadora. Os valores obtidos correspondem a concentrações de bicarbonato, já que nem carbonatos ou hidróxidos foram caracterizados.

A determinação dos sólidos totais em suspensão (STS) consistiu em separar os sólidos suspensos por filtração de um determinado volume através de membrana Millipore de $47 \mathrm{~mm}$ de diâmetro e $0,45 \mu \mathrm{m}$ de porosidade. Após a filtragem, levou-se a membrana a secar por um período de 24 horas. Em seguida, efetuaram-se pesagens sucessivas dessa membrana até a obtenção de valores constantes. $\mathrm{O}$ valor de STS foi expresso como uma razão entre a massa de material retido e o volume de amostra (Tonetto e Bonotto, 1999).

As determinações de BTEX e HPA foram realizadas pelo Laboratório de Química Ambiental do Instituto de Química da USP de São Carlos (IQSC) de acordo com as metodologias USEPA 8015 e 8270 , respectivamente.

\section{Análises microbiológicas}

A contagem de bactérias heterotróficas totais nas amostras de água subterrânea foi realizada com a técnica pour plate em placas contendo o meio PCA (Acumedia, EUA), incubadas durante $48 \mathrm{~h}$ a $35^{\circ} \mathrm{C}$.

As metodologias descritas em Aaronson (1970) foram utilizadas para averiguar a presença na água subterrânea (ponto SB3, $1^{\text {a }}$ coleta) de bactérias oxidadoras de benzeno e tolueno e bactérias Pseudomonas capazes de degradar naftaleno.

A verificação qualitativa da presença de coliformes totais e da bactéria Escherichia coli foi realizada com plaqueamento (pour plate, $48 \mathrm{~h}$ a $35^{\circ} \mathrm{C}$ ) utilizando-se o meio de cultura agar chromocult $^{\circledR}$ (Merck, Alemanha). As colônias são diferenciadas pela cor: coliformes totais (violeta) e E. coli (rosa).

\section{Teste de biodegradabilidade utilizando o indicador redox DCPIP}

Amostra coletada no ponto SB3 ( $4^{\text {a }}$ coleta) foi utilizada para determinar 
se os microrganismos presentes na água subterrânea eram capazes de biodegradar óleo diesel de dois tipos, um comprado em um posto de combustíveis (diesel comercial) e outro coletado da fase livre decorrente de um vazamento em outro posto de combustíveis, chamado aqui como "diesel intemperizado", já que análises cromatográficas (não mostradas nesse trabalho) evidenciam que as concentrações de hidrocarbonetos presentes no óleo intemperizado foram alteradas devido a processos físico-químicos e microbiológicos (Mariano, 2006).

Os testes de biodegradabilidade foram realizados usando a técnica baseada no indicador redox 2,6-diclorofenol indofenol (DCPIP) (Hanson et al, 1993). Para se preparar o inóculo, $1 \mathrm{~mL}$ da amostra SB3 foi estriada em placa de Petri contendo meio nutriente agar. As placas foram incubadas durante 24 horas a $35^{\circ} \mathrm{C}$ e então as culturas foram removidas com água estéril. Em frascos Erlenmeyers estéreis (125 mL, duplicatas) contendo $50 \mathrm{~mL}$ de meio Bushnell-Hass (BH) e óleo diesel $(1 \% \mathrm{v} / \mathrm{v}), 1 \mathrm{~mL}$ do inóculo e $20 \mathrm{mg} / \mathrm{mL}$ de DCPIP foram adicionados. Os frascos foram mantidos sob agitação (240 rpm) em temperatura ambiente $\left(27 \pm 2^{\circ} \mathrm{C}\right)$. O meio $\mathrm{BH}$ é composto por, g. $\mathrm{L}^{-1}: \mathrm{MgSO}_{4}: 0,2 ; \mathrm{CaCl}_{2}: 0,02$; $\mathrm{KH}_{2} \mathrm{PO}_{4}: 1,0 ; \mathrm{K}_{2} \mathrm{HPO}_{4}: 1,0 ; \mathrm{NH}_{4} \mathrm{NO}_{3}: 1,0$; $\mathrm{FeCl}_{3}: 0,05$ (Difco, 1984).

O princípio deste teste é que durante a oxidação microbiana dos hidrocarbonetos, elétrons são transferidos até aceptores como oxigênio, nitrato e sulfato. Ao incorporar um aceptor de elétron como o DCPIP ao meio de cultura, é possível averiguar a capacidade dos microrganismos em utilizar hidrocarbonetos como substrato pela observação da mudança de cor do DCPIP de azul (oxidado) para incolor (reduzido). Esta técnica desenvolvida por Hanson et al. (1993) tem sido utilizada em vários trabalhos, por exemplo, Cormack e Fraile (1997), Roy et al (2002), Peixoto e Vieira (2005), Lovaglio et al. (2005), Silva et al (2005), Souza et al (2005) e Mariano (2006).

\section{RESULTADOS E DISCUSSÃO}

Resultados obtidos a partir das determinações efetuadas nas amostras de água subterrânea coletadas entre maio de 2004 e abril de 2006 são mostrados nas Tabelas 1 até 5 .

A partir dos dados de concentra- ção dos íons maiores (Tabelas 2 e 3 ) foi feita a classificação hidroquímica da água subterrânea com o auxílio do diagrama de Piper (Piper, 1944). A classificação é baseada na concentração relativa dos íons dominantes. Para adicionar dados nesses diagramas, transformam-se os valores de cada íon expresso em meq/L, em percentagem do total de ânions e do total de cátions, separadamente (Freeze e Cherry, 1979).
Em todas as coletas, as amostras foram classificadas como bicarbonatada sódica, com exceção do ponto SB1 na $1^{\text {a }}$ coleta, classificada como bicarbonatada sulfatada. Assim, no geral, os resultados obtidos em todas as coletas são semelhantes aos representados no diagrama da Figura 2, que mostra os dados da $2^{\text {a }}$ coleta.

Observações de campo em relação ao poço de monitoramento SB1, como

Tabela I - Valores de nível dos poços de monitoramento, temperatura, condutividade, oxigênio dissolvido, $\mathrm{pH}$, e potencial redox para as amostras de água subterrânea coletadas entre maio de 2004 e abril de 2006

\begin{tabular}{|c|c|c|c|c|c|c|c|}
\hline $\begin{array}{l}\text { poço } \\
\text { monit. }\end{array}$ & $\begin{array}{l}\text { data } \\
\text { coleta }\end{array}$ & $\begin{array}{l}\text { nível } \\
(\mathrm{m})\end{array}$ & $\begin{array}{c}\mathrm{T} \\
\left({ }^{\circ} \mathrm{C}\right)\end{array}$ & $\begin{array}{c}\text { condutividade } \\
\left(25^{\circ} \mathrm{C}\right) \\
\left(\mathrm{mS} . \mathrm{cm}^{-1}\right)\end{array}$ & $\begin{array}{c}\mathrm{OD} \\
\left(\mathrm{mg} \cdot \mathrm{L}^{-1}\right)\end{array}$ & $\mathrm{pH}$ & $\begin{array}{c}\text { Eh } \\
(\mathrm{mV})\end{array}$ \\
\hline \multirow[t]{4}{*}{ SB1 } & 01/mai/04 & 2,46 & 25,0 & 0,308 & 4,4 & 6,0 & 14 \\
\hline & 29/abr/05 & 1,80 & 25,6 & 0,241 & 1,1 & 6,2 & 72 \\
\hline & 08/nov/05 & 1,27 & 25,0 & 0,378 & 2,2 & 5,8 & -46 \\
\hline & 10/abr/06 & 1,17 & 25,7 & 0,860 & 1,1 & 5,8 & 48 \\
\hline \multirow[t]{4}{*}{ SB2 } & 01/mai/04 & 1,69 & 26,3 & 0,173 & 4,6 & 6,2 & 203 \\
\hline & 29/abr/05 & 1,73 & 27,4 & 0,179 & 2,8 & 6,4 & 117 \\
\hline & 08/nov/05 & 2,33 & 25,3 & 0,310 & 5,0 & 6,3 & 215 \\
\hline & 10/abr/06 & 1,80 & 27,0 & 0,620 & 4,6 & 6,1 & 198 \\
\hline \multirow[t]{4}{*}{ SB3 } & 01/mai/04 & 3,60 & 25,2 & 0,254 & 4,3 & 6,5 & 53 \\
\hline & $29 / \mathrm{abr} / 05$ & 3,06 & 25,5 & 0,235 & 1,4 & 5,9 & 89 \\
\hline & 08/nov/05 & 2,88 & 24,5 & 0,281 & 2,6 & 5,9 & 75 \\
\hline & 10/abr/06 & 3,02 & 26,0 & 0,260 & 4,5 & 5,8 & 187 \\
\hline
\end{tabular}

Tabela 2 - Valores de sódio, cloro, magnésio, cálcio, fosfato e potássio para as amostras de água subterrânea coletadas entre maio de 2004 e abril de 2006

\begin{tabular}{cccccccc}
\hline $\begin{array}{c}\text { poço } \\
\text { monit. }\end{array}$ & $\begin{array}{c}\text { data } \\
\text { coleta }\end{array}$ & $\mathrm{Na}$ & $\mathrm{Cl}$ & $\begin{array}{c}\mathrm{Mg} \\
\left(\mathrm{mg} . \mathrm{L}^{-1}\right)\end{array}$ & $\mathrm{Ca}$ & $\mathrm{PO}_{4}^{3-}$ & $\mathrm{K}$ \\
\hline SB1 & 01/mai/04 & 26,2 & 6,40 & 0,00 & 0,38 & 0,05 & 6,90 \\
& 29/abr/05 & 33,2 & 11,4 & 0,07 & 0,36 & 0,53 & 20,6 \\
& 08/nov/05 & 38,9 & 15,6 & $<0,01$ & 0,64 & 3,16 & 19,0 \\
& 10/abr/06 & 64,5 & 12,7 & 0,05 & 0,58 & 2,86 & 4,55 \\
SB2 & 01/mai/04 & 14,9 & 7,60 & 0,06 & 0,57 & 0,20 & 6,30 \\
& 29/abr/05 & 14,3 & 3,20 & 0,01 & 0,57 & 0,12 & 18,2 \\
& 08/nov/05 & 20,9 & 16,6 & 0,12 & 0,36 & 0,19 & 69,0 \\
& 10/abr/06 & 15,9 & 3,20 & $<0,01$ & 0,60 & 0,18 & 4,86 \\
SB3 & 01/mai/04 & 19,4 & 2,90 & 0,03 & 0,51 & 0,09 & 4,61 \\
& 29/abr/05 & 18,8 & 6,00 & 0,07 & 0,41 & 0,11 & 4,57 \\
& $08 /$ nov/05 & 25,8 & 17,7 & 0,04 & 0,41 & 0,07 & 2,99 \\
& 10/abr/06 & 27,8 & 9,40 & $<0,01$ & 0,51 & 0,14 & 4,55 \\
\hline
\end{tabular}


Tabela 3 - Valores de sulfato, ferro (II), nitrato, sólidos totais em suspensão e alcalinidade para as amostras de água subterrânea coletadas entre maio de 2004 e abril de 2006

\begin{tabular}{ccccccc}
\hline $\begin{array}{c}\text { poço } \\
\text { monit. }\end{array}$ & $\begin{array}{c}\text { Data } \\
\text { coleta }\end{array}$ & $\mathrm{SO}_{4}^{2-}$ & $\mathrm{Fe}(\mathrm{II})$ & $\begin{array}{c}\mathrm{NO}_{3}^{-} \\
\left(\mathrm{mg} . \mathrm{L}^{-1}\right)\end{array}$ & STS* $^{*}$ & alcalinidade** $^{* *}$ \\
\hline SB1 & $01 / \mathrm{mai} / 04$ & 62 & $<0,01$ & 0,50 & 8,0 & 52,0 \\
& $29 / \mathrm{abr} / 05$ & 13 & 0,03 & 5,05 & 80 & 178 \\
& $08 / \mathrm{nov} / 05$ & 27 & 1,30 & 1,90 & 10 & 72,0 \\
& $10 / \mathrm{abr} / 06$ & 33 & 3,22 & 1,94 & 10 & 114 \\
SB2 & $01 / \mathrm{mai} / 04$ & 11 & 0,01 & 0,08 & 8,0 & 39,0 \\
& $29 / \mathrm{abr} / 05$ & 8,0 & 0,02 & 0,26 & 10 & 51,0 \\
& $08 / \mathrm{nov} / 05$ & 8,0 & 0,03 & 0,28 & 20 & 77,0 \\
& $10 / \mathrm{abr} / 06$ & 19 & 0,06 & 0,39 & 10 & 44,5 \\
SB3 & $01 / \mathrm{mai} / 04$ & 17 & $<0,01$ & 1,11 & 80 & 95,0 \\
& 29/abr/05 & 4,0 & 0,79 & 1,54 & 10 & 72,0 \\
& $08 / \mathrm{nov} / 05$ & 9,0 & 0,01 & 0,38 & 80 & 67,0 \\
& $10 / \mathrm{abr} / 06$ & 1,0 & 0,47 & 0,87 & 20 & 67,5 \\
\hline
\end{tabular}

* sólidos totais em suspensão

** alcalinidade expressa como $\mathrm{HCO}_{3}$

Tabela 4- Concentração de BTEX nas amostras de água subterrânea coletadas entre maio de 2004 e abril de 2006

\begin{tabular}{|c|c|c|c|c|c|c|}
\hline $\begin{array}{l}\text { poço } \\
\text { monit. }\end{array}$ & $\begin{array}{c}\text { data } \\
\text { coleta }\end{array}$ & benzeno & tolueno & $\begin{array}{c}\text { etil- } \\
\text { benzeno } \\
\left(\mu \mathrm{g} . \mathrm{L}^{-1}\right)\end{array}$ & xilenos & Total \\
\hline \multirow[t]{4}{*}{ SB1 } & 01/mai/04 & $<\mathrm{LD}^{1}$ & $<\mathrm{LD}$ & $<\mathrm{LD}$ & $<\mathrm{LD}$ & $<\mathrm{LD}$ \\
\hline & $29 / \mathrm{abr} / 05$ & $<\mathrm{LD}$ & $<\mathrm{LD}$ & $<\mathrm{LD}$ & $<\mathrm{LD}$ & $<\mathrm{LD}$ \\
\hline & 08/nov/05 & $<\mathrm{LD}$ & $<\mathrm{LD}$ & $<\mathrm{LD}$ & $<\mathrm{LD}$ & $<\mathrm{LD}$ \\
\hline & $10 / \mathrm{abr} / 06$ & $<\mathrm{LD}$ & $<\mathrm{LD}$ & 4330 & 372 & 4702 \\
\hline \multirow[t]{4}{*}{ SB2 } & 01/mai/04 & $<\mathrm{LD}$ & $<\mathrm{LD}$ & $<\mathrm{LD}$ & $<\mathrm{LD}$ & $<\mathrm{LD}$ \\
\hline & 29/abr/05 & $<\mathrm{LD}$ & $<\mathrm{LD}$ & $<\mathrm{LD}$ & $<\mathrm{LD}$ & $<\mathrm{LD}$ \\
\hline & 08/nov/05 & $<\mathrm{LD}$ & $<\mathrm{LD}$ & $<\mathrm{LD}$ & $<\mathrm{LD}$ & $<\mathrm{LD}$ \\
\hline & 10/abr/06 & 49 & 69 & 90 & 99 & 307 \\
\hline \multirow[t]{4}{*}{ SB3 } & 01/mai/04 & 9,0 & 11,4 & 13,4 & 22,3 & 56,1 \\
\hline & 29/abr/05 & $<\mathrm{LD}$ & $<\mathrm{LD}$ & $<\mathrm{LD}$ & $<\mathrm{LD}$ & $<\mathrm{LD}$ \\
\hline & 08/nov/05 & $<\mathrm{LD}$ & $<\mathrm{LD}$ & $<\mathrm{LD}$ & $<\mathrm{LD}$ & $<\mathrm{LD}$ \\
\hline & $10 / \mathrm{abr} / 06$ & 57 & $<\mathrm{LD}$ & 914 & 334 & 1305 \\
\hline \multicolumn{2}{|c|}{ intervenção ${ }^{2}$} & 5 & 700 & 300 & 500 & \\
\hline \multicolumn{2}{|c|}{ referência ${ }^{3}$} & 5 & - & - & - & \\
\hline
\end{tabular}

${ }^{1} \mathrm{LD}$ (limite de detecção) $=4,0 \mu \mathrm{g} \cdot \mathrm{L}^{-1}$

${ }^{2}$ CETESB- "Valores orientadores para avaliação de solos e águas subterrâneas, Novembro de 2005."

${ }^{3}$ Portaria 518, 21 de Dezembro de 2004 do Ministério da Saúde. 
Tabela 5 - Concentração de hidrocarbonetos policíclicos aromáticos (HPA) nas amostras de água subterrânea coletadas em abril de 2006

\begin{tabular}{ccccc}
\hline HPA & SB1 & SB2 & SB3 & intervenção $^{2}$ \\
\hline Naftaleno & \multicolumn{2}{c}{$\left(\mu \mathrm{g} \cdot \mathrm{L}^{-1}\right)$} & \\
Acenaftileno & $<\mathrm{LD}^{1}$ & 2,56 & 12,09 & 140 \\
Fluoreno & 1,15 & 4,97 & 4,54 & - \\
Antraceno & 2,34 & 0,87 & 2,87 & - \\
Pireno & $<\mathrm{LD}$ & 6,12 & 1,97 & - \\
Benzo (a) Antraceno & $<\mathrm{LD}$ & $<\mathrm{LD}$ & $<\mathrm{LD}$ & 1,75 \\
Criseno & 5,18 & 0,87 & $<\mathrm{LD}$ & - \\
Benzo (k) Fluoranteno & $<\mathrm{LD}$ & $<\mathrm{LD}$ & $<\mathrm{LD}$ & - \\
Benzo (a) Pireno & $<\mathrm{LD}$ & 0,02 & 0,032 & $0,77^{3}$ \\
Dibenzo (a,h) Antraceno & $<\mathrm{LD}$ & $<\mathrm{LD}$ & $<\mathrm{LD}$ & 0,18 \\
Benzo (g,h,i) Pirileno & 6,09 & $<\mathrm{LD}$ & $<\mathrm{LD}$ & - \\
Indeno (1,2,3) Pireno & $<\mathrm{LD}$ & $<\mathrm{LD}$ & $<\mathrm{LD}$ & 0,17 \\
Fenantreno & 0,05 & 1,91 & 7,12 & 140 \\
Fluoranteno & $<\mathrm{LD}$ & $<\mathrm{LD}$ & $<\mathrm{LD}$ & - \\
Benzo (b) Fluoranteno & 0,07 & 0,054 & $<\mathrm{LD}$ & - \\
Total & 15 & 17 & 29 & \\
\hline
\end{tabular}

${ }^{1} \mathrm{LD}$ (limite de detecção) $=0,01 \mu \mathrm{g} \cdot \mathrm{L}^{-1}$

${ }^{2}$ CETESB- "Valores orientadores para avaliação de solos e águas subterrâneas, Novembro de 2005."

${ }^{3}$ Valor também estipulado pela Portaria 518, 21 de Dezembro de 2004 do Ministério da Saúde

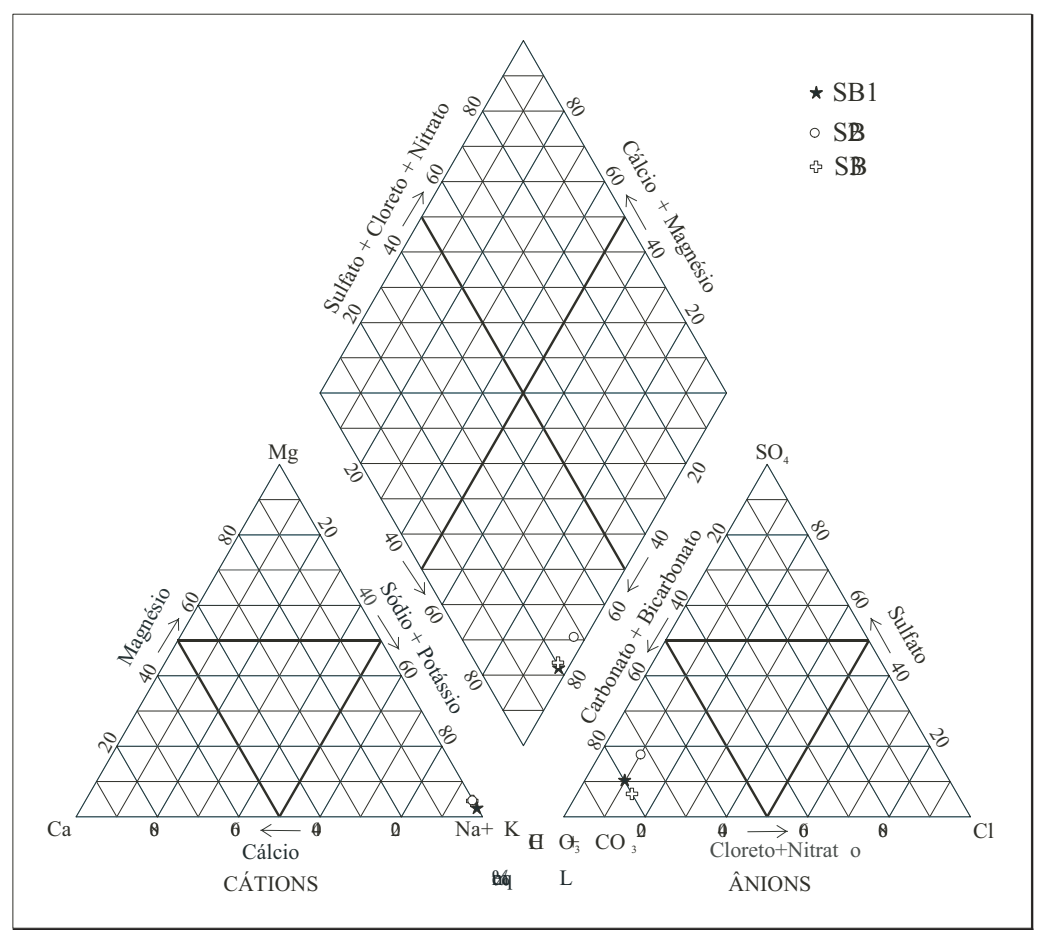

Figura 2 - Diagrama de Piper efetuado a partir de dados obtidos com a coleta de amostras de água subterrânea realizada em abril de 2005 (2a coleta). 
odor de $\mathrm{H}_{2} \mathrm{~S}$ e rápida recuperação em relação aos outros poços, levantaram a suspeita da possibilidade de infiltração de água proveniente da rede de esgoto. Teste realizado em laboratório (plaqueamento em meio agar chromocult ${ }^{\circledR}$ ), cuja finalidade consistiu na verificação da presença de bactérias do grupo coliformes totais e a bactéria Escherichia coli, mostrou que os três pontos de coleta apresentavam $E$. coli, sendo que somente no ponto SB1 foram verificados os coliformes totais. A bactéria E. coli em outros estudos (Sorkhoh et al, 1990; Al-Hadhrami et al, 1995) foi considerada como capaz de biodegradar hidrocarbonetos, contudo, a presença dos coliformes é um forte indício da infiltração de esgoto doméstico. Outros parâmetros (Tabelas 1 a 3) também são indicativos quando são comparados os valores obtidos para SB2 relativamente à SB1, que estão situados proximamente, por exemplo, menor concentração de oxigênio dissolvido, e maiores concentraçôes de sódio, fosfato, sulfato e nitrato. Portanto, devido a esta possível influência externa, é conveniente não considerar os valores medidos no ponto SB1 na análise dos indicadores geoquímicos.

Fatores importantes para a avaliação da biorremediação natural como a caracterização da composição natural da água subterrânea (background) e a delimitação da pluma de contaminação não foram possíveis de serem obtidos devido ao número reduzido de poços de monitoramento na área. Apesar disso, com as análises realizadas é possível verificar alguns parâmetros que indicam a biodegradação dos contaminantes, como a presença de microrganismos hidrocarbonoclásticos na água subterrânea.

De acordo com a metodologia proposta por Aaronson (1970), foi verificada a presença, na amostra coletada no ponto SB3, de bactérias Pseudomonas oxidadoras de naftaleno, e bactérias capazes de biodegradar benzeno e tolueno. A verificação da presença desses microrganismos na água subterrânea é importante uma vez que o naftaleno, um composto aromático policíclico (HPA) característico na composição de óleo diesel, bem como o benzeno e o tolueno, estão especificados na lista de referência de valores de intervenção para águas subterrâneas da CETESB (CETESB, 2005).

No teste utilizando-se o indicador redox DCPIP, a descoloração do meio de cultivo ocorreu em 3 dias para ambos os óleos diesel testados (comercial e intemperizado). Esse resultado mostra que os microrganismos presentes na água subterrânea apresentam capacidade de degradar o óleo diesel mesmo este estando intemperizado, ou seja, no local há uma microbiota adaptada para degradar hidrocarbonetos recalcitrantes, onde cada espécie tem uma função específica nas seqüências de reações enzimáticas responsáveis pela quebra de cadeias complexas de hidrocarbonetos.

Rosenberg e Gutnick (1981) concluíram que bactérias capazes de degradarem hidrocarbonetos estão localizadas potencialmente em todas as áreas naturais, embora apresentem grandes variações em suas concentrações celulares. No entanto, é importante ressaltar que apenas a constatação da presença desses microrganismos não significa que esteja ocorrendo no local contaminado uma biorremediação efetiva. Segundo Corseuil (1994), é importante também verificar a presença de biomassa suficiente para a degradação dos contaminantes, pois pequenas populaçôes de microrganismos contaminantes-específicos podem resultar em significantes períodos de retardo antes do início de uma biodegradação mensurável. A água subterrânea contaminada com hidrocarbonetos contem frequentemente maiores densidades populacionais microbianas que a água subterrânea natural do local. Este aumento está relacionado à fonte su- plementar de carbono oferecida pelos hidrocarbonetos (Riser-Roberts, 1992). De acordo com USEPA (1987) apud Shaffner e Juneau (1995), amostras de água subterrânea coletadas a montante de locais contaminados com hidrocarbonetos tipicamente apresentam uma densidade populacional total de aproximadamente $10^{2}$ a $10^{3}$ unidades formadoras de colônias por mililitro (UFC. $\mathrm{mL}^{-1}$ ). A população de bactérias heterotróficas totais nas amostras de água subterrânea em todas as coletas $(\mathrm{Fi}-$ gura 3) variou entre $10^{4}$ e $10^{6} \mathrm{UFC}_{\mathrm{mL}} \mathrm{m}^{-1}$, valores compatíveis com a baixa concentração de hidrocarbonetos verificada na água subterrânea durante o período de monitoramento.

Os resultados das análises físicoquímicas da água subterrânea realizadas durante o período de monitoramento de dois anos (Tabelas 1 a 3) também fornecem parâmetros que indicam condições favoráveis à biodegradação dos contaminantes, como temperatura próxima a $25^{\circ} \mathrm{C}, \mathrm{pH}$ ligeiramente ácido e condições oxidantes (valores positivos de Eh). Contudo a baixa concentração de fósforo dissolvido $\left(\mathrm{PO}_{4}^{3-}\right)$ pode ser um fator limitante.

Nas datas em que foi constatada a presença de hidrocarbonetos na água subterrânea, as concentrações de BTEX no ponto SB3, próximo ao local do vazamento, sempre foram maiores que aquelas encontradas em SB2 que está à jusante (Tabela 4), sendo que somente no primeiro foi detectada fase livre. Esta diminuição pode ser atribuída a processos como advecção, diluiçãa,

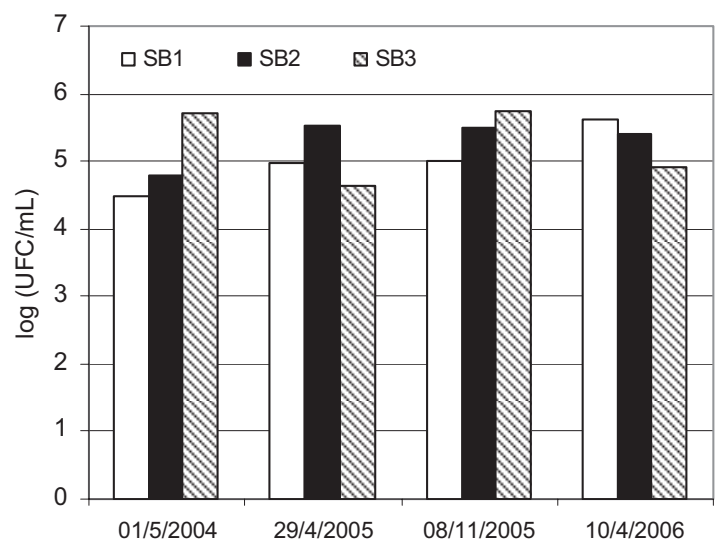

Figura 3 - Contagem de bactérias heterotróficas totais nas amostras de água subterrânea coletadas entre maio de 2004 e abril de 2006 
dispersão, sorção, volatilização e também à biodegradação, pois níveis de oxigênio dissolvido e alcalinidade são, respectivamente, menores e maiores em SB3. Em locais onde esteja ocorrendo processos aeróbios de biodegradação, a concentração de oxigênio diminui nos locais de maior concentração de hidrocarbonetos devido ao consumo destes pelos microrganismos e como produto desse metabolismo tem-se a produção de $\mathrm{CO}_{2}$, que causa o aumento da alcalinidade. Os indicadores geoquímicos também indicam que processos anaeróbios de biodegradação possivelmente não estão ocorrendo, uma vez que o aquiífero apresenta condiçōes oxidantes e a variação das concentraçóes de nitrato, sulfato, e Fe (II) entre SB3 e SB2 não são significativas.

$\mathrm{Na}$ última coleta, após um ano em que a concentração de BTEX esteve abaixo do nível de detecção, houve um aumento considerável na concentração destes contaminantes (Tabela 4). Isto indica que hidrocarbonetos retidos ou adsorvidos no solo representam uma fonte constante de contaminação. $\mathrm{Na}$ data da realização da $1^{\text {a }}$ coleta foi feita uma amostragem de solo próxima ao ponto SB3 até a profundidade da franja capilar (2,60 m) (Mariano, 2006). Análises para quantificação dos hidrocarbonetos totais (HTP) acusaram a presença desses contaminantes no solo. Na mesma data da última coleta, também foi realizada a análise dos hidrocarbonetos policíclicos aromáticos (HPA) e os valores não se encontraram acima daqueles permitidos pela legislação (Tabela 5). Em SB3, as concentraçôes de benzeno e etilbenzeno estão acima do valor de intervenção determinado pela Cetesb, sendo este valor definido como "a concentração de determinada substância no solo ou na água subterrânea acima da qual existem riscos potenciais, diretos ou indiretos, à saúde humana, considerado um cenário de exposição genérico" (CETESB, 2005). Nestes casos, o órgão ambiental indica a necessidade de ações para resguardar os receptores de risco. À jusante de SB3, em SB2, as concentraçōes diminuem e apenas a concentração de benzeno continua acima dos valores permitidos pela legislação. Segundo Border et al (1995), a taxa de biodegradação de compostos aromáticos em ambientes aeróbios pode ser bastante alta, portanto é muito provável que mais à jusante a concentração deste contaminante atinja valores aceitáveis. Considerando que nesta região não há captação de água subterrânea para abastecimento público, a biorremediação natural monitorada é uma opção bastante adequada de saneamento, sendo que a instalação de novos poços de monitoramento à jusante de SB2 seria imprescindível para uma confirmação mais precisa da extensão dessa pluma.

\section{CONCLUSÕES}

A partir de ensaios laboratoriais e do monitoramento da água subterrânea, ainda que através de um número reduzido de poços de monitoramento, foi possível identificar fatores que corroboram o emprego da técnica de biorremediação natural para o tratamento da água subterrânea contaminada em decorrência do vazamento de óleo diesel no posto de combustíveis. A presença de microrganismos capazes de biodegradar hidrocarbonetos, a disponibilidade de oxigênio dissolvido e a diminuição da concentração de hidrocarbonetos ao longo do sentido do fluxo da água subterrânea são indicativos de que está ocorrendo a biodegradação. Contudo, a presença de hidrocarbonetos retidos no solo representa uma fonte contínua de contaminação, e por isso faz-se necessário o monitoramento a longo prazo.

\section{AGRADECIMENTOS}

Os autores agradecem à Agência Nacional do Petróleo, Gás Natural e Biocombustíveis (ANP) (PRH-05) pelo apoio financeiro, ao proprietário e funcionários do posto de combustíveis eà Bruce Wilton Tessari (auxiliar de campo).

\section{REFERÊNCIAS}

AARONSON, S. Experimental Microbial Ecology. London, Academic Press, 1970.

AL-HADHRAMI, M. N.; LAPPIN-SCOTT, H. M.; FISHER, P. J. Bacterial survival and n-alkane degradation within Omani crude oil and a mousse. Marine Pollution Bull., v.30, n.6, p.403-408, 1995.

ALEXANDER, M. Biodegradation and Bioremediation. 302 p, Academic Press, 1994.

AZADPOUR-KEELEY, A.; RUSSELL, H. H.; SEWELL, G. W. Microbial Processes Affecting Monitored Natural Attenuation of Contaminants in the Subsurface. EPA-Ground Water Issue. 18p, 1999.

BENTO, F. M.; CAMARGO, F. A. O.; OKEKE, B. Bioremediation of soil contaminated by diesel oil. Brazilian Journal of Microbiology, v.34, p.65-68, 2003.
BHUPATHiRajU, V. K. et al. Assessment of in-situ bioremediation at a refinery waste-contaminated site and an aviation gasoline contaminated site. Biodegradation, v. 13, p. 79-90, 2002.

BORDEN, R. C.; GOMEZ, C. A.; BECKER, M. T. Geochemical indicators of intrinsic bioremediation. Ground Water, v. 33, n. 2, p.180-189, 1995.

BRASIL, Leis, etc. Portaria n. 518 de 25 de março de 2004. Disponível em: http://www. funasa.gov.br/sitefunasa/legis/pdfs/portarias m/pm_518_2004.pdf. Acesso em 23 de Julho de 2004, 2004.

CETESB - COMPANHIA DE TECNOLOGIA DE SANEAMENTO AMBIENTAL. Relatório de estabelecimento de valores orientadores para solos e águas subterrâneas no Estado de São Paulo. Relatório técnico. Disponível em: http://www.cetesb.sp.gov. br. Acesso em 18 de Junho de 2006, 2005.

CHEON, J. Y.; LEE, J. Y.; LEE, K. K. Characterization of the hydrogeologic environment at a petroleum hydrocarbon contaminated site in Korea. Environmental Geology, v. 45, p. 869-883, 2004.

CORMACK, W. P. M.; FRAILE, E. R. Chanacterization of a hydrocarbon degrading psychrotrophic Antarctic bacterium. Antarctic Science, v.9, n.2, p.150-155, 1997.

CORSEUIL, H. X. Limitaçôes da biomassa autóctone na degradação de compostos tóxicos em subsolos. Revista Bio, v.3, n.2, p.46-56, 1994.

CORSEUIL, H. X.; ALVAREZ, P. J. J. Natural bioremediation perspective for BTX-contaminated groundwater in Brazil: effect of ethanol. Wat. Sci. Tech., v. 34, n. 7-8, p.311-318, 1996.

CORSEUIL, H. X.; MARINS, M. D. M. Contaminação de água subterrânea por derramamento de gasolina: O problema é grave? Engenharia Sanitária, v. 2, p.50-54, 1997.

CUNHA, C. D.; LEITE, S. G. F. Gasoline biodegradation in different soil microcosms. Braz. J. of Microb., v.31, p. 45-49, 2000.

DIFCO. Difco Manual. 10ed. Detroit: Difco Laboratories, 1984.

FREEZE, R. A.; CHERRY, J. A. Groundwater. Prentice Hall, Inc. New Jersey. p.604, 1979.

GELHAR, L. W.; WELTY, C.; REHFELDT, K. R. A Critical Review of Data on Field-scale Dispersion in Aquifers. Water Resour. Res., v. 28, n. 7, p.1955-1974, 1992.

HACH. Water Analysis Handbook, 2a ed., Hach Co., Loveland, 831 p., 1992.

HANSON, K. G.; DESAI, J. D.; DESAI, A. J. A rapid and simple screening technique for potential crude oil degrading microorganisms. Biotechnology Techniques, v. 7, p. 745-748, 1993.

HUNKELER, D.; HÖHENER, P.; ZEYER, J. Engineered and subsequent intrinsic insitu bioremediation of a diesel fuel contaminated aquifer. Journal of Contaminant Hydrology, v. 59, p. 231-245, 2002.

KAO, C. M., WANG, C. C. Control of BTEX migration by intrinsic bioremediation at a gasoline spill site. Wat. Res. v. 34, n.13, p. 3413-3423, 2000.

LOVAGLIO, R. B. et al. Biodegradação de querosene por leveduras da regiāo portuária de Suape-PE. In: First Braziliam Symposium on Petroleum Biotechnology, Natal - RN, Brazil, 2005. 
MARIANO, A. P. Avaliação do potencial de biorremediação de solos éaguas subterrâneas contaminados com óleo diesel. Rio Claro, SP. Tese (Doutorado) - Instituto de Geociências e Ciências Exatas, Universidade Estadual Paulista (Unesp), 2006.

MARIANO, A. P.; et al. Laboratory study on the bioremediation of diesel oil contaminated soil from a petrolstation. Brazilian Journal of Microbiology, v. 38 (2), p. 346-353, 2007.

PEIXOTO, R. M.; VIEIRA, J. D. G. Determination of the degrading potential of bacteria isolated from an environment impacted by petroleum and derivatives using 2,6-dichlorophenolindophenol (DCPIP). In: FIRST BRAZILIAM SYMPOSIUM ON PETROLEUM BIOTECHNOLOGY, Natal - RN, Brasil, 2005.

PIPER, A. M. Agraphic procedure in the geochemical interpretation of water-analyses. Trans. Amer Geophysical Union, v.25, p. 914-928, 1944.

RISER-ROBERTS, E. Bioremediation of petroleum contaminated sites. Boca Ratón, FL. CRC Press, 1992.

RÖLING, W. F. M.; VERSEVEL, H. W. Natural attenuation: What does the subsurface have in store? Biodegradation, v.13, p. 53-64, 2002.

ROSENBERG, M.; GUTNICK, D. L. The bydrocarbon-oxidizing bacteria. In: STARR, M. P., STOLP, H., TRUPER, G. H., BALOWS, A., SCHLEGEL, H. G. The prokaryotes. New York, Springer-Verlag, 1981.

ROY, S. et al. Survey of petroleum-degrading bacteria in coastal waters of Sunderban Biosphere Reserve. World Journal of Microbiology \& Biotechnology, v. 18, p. 575-581, 2002.

SCHAFFNER, I. R.; JUNEAU, A. A. In-Situ Air Sparging Without Inorganic Nutrient Amendment: An Effective Bioremediation Strategy For Treating Petroleum-Contaminated Groundwater Systems.In: The Nineth National Outdoor Action Conference on Aquifer Remediation, Ground
Water Monitoring, \& Geophysical Methods: National Ground Water Association, p. 101-115. Disponível em: http://www.bioremediationgroup.org/BioReferences/Tier1Papers/insitu. htm. Acesso em 20 de Junho de 2006, 1995.

SILVA, R. L. B. et al. Estudo da contaminação de poços rasos por combustiveis orgânicos e possiveis conseqüências para a saúde pública no Município de Itaguai, Rio de Janeiro, Brasil. Caderno Saúde Pública, v.18, n.6, p. 1599-1607, 2002.

SILVA, M. R. O. et al. Seleção de linhagens, isoladas e em consórcios, com potencialidade para degradar óleo diesel. In: FIRST BRAZILIAM SYMPOSIUM ON PETROLEUM BIOTECHNOLOGY, Natal - RN, Brasil, 2005.

SORKHOH, N. A. et al. Crude oil and hydrocarbon-degrading strains of Rhodococcus rhodochous isolated from soil and marine environment in Kuwait. Environ. Pollution, v. 65 , p.1-17, 1990.

SOUZA, C. S. et al. Isolamento e seleção de microrganismos degradadores de derivados de petróleo. In: $3^{\circ}$ CONGRESSO BRASILEIRO DE P\&D EM PETRÓLEO E GÁS. Salvador-BA-Brasil, 2005.

TONETTO, E. M.; BONOTTO, D. M. Implementação de metodologia para a análise química de águas e sua aplicação na caracterização das águas subterrâneas de Aguas da Prata (SP). Geociências, v. 18 , n. 2, p. 303-325, 1999.

VROBLESKY, D. A.; CHAPELLE, F. H. Temporal and spatial changes of terminal electronaccepting processes in a petroleum hydrocarbon-contaminated aquifer and the significance for contaminant biotransformation. Water Resource Res., v. 30, n. 5, p.1561-1570, 1994.

WALT, W.; McNAB Jr. Comparisons of geochemical signatures of biotransformation of fuel hydrocarbons in groundwater. Environmental Monitoring and Assessment, v. 59, p. 257-274, 1999.
WATERLOO. Caracterizaçāo Geológica, Hidrogeológica e Análise Qualitativa da Contaminação no Solo e na Agua Subterrânea. Relatório técnico da Waterloo Hydrogeologic Brasil, São Paulo, p.40, 1999.

ZOBELL, C. E. Studies on redox potential of marine sediments. Bull. Am. Assoc. Petrol. Geologists, v.30, p. 477-509, 1946.

Endereço para correspondência:

\author{
Adriano Pinto Mariano \\ Universidade Estadual Paulista \\ - Unesp \\ Av. 24-A, I5I5 - CP 199 \\ I3506-900 - Rio Claro - SP \\ - Brasil \\ Tel.: (I9) 3526-4I77 \\ Fax: (19) 3526-4I76 \\ Email: adrianomariano@yahoo.com.br
}

